\title{
Subsidized Housing, Public Housing, and Adolescent Violence and Substance Use
}

\author{
Tamara G. J. Leech \\ Indiana University-Purdue University, Indianapolis
}

Tamara G. J. Leech, Department of Sociology, Indiana University-Purdue University, 425 University Boulevard, 301E Cavanaugh Hall, Indianapolis, IN 46202 Email: tleech@iupui.edu

\begin{abstract}
This study examines the separate relationships of public housing residence and subsidized housing residence to adolescent health risk behavior. Data include 2,530 adolescents aged 14 to 19 who were children of the National the Longitudinal Study of Youth. The author use stratified propensity methods to compare the behaviors of each group — subsidized housing residents and public housing residents — to a matched control group of teens receiving no housing assistance. The results reveal no significant relationship between public housing residence and violence, heavy alcohol/marijuana use, or other drug use. However, subsidized housing residents have significantly lower rates of violence and hard drug use, and marginally lower rates of heavy marijuana/alcohol use. The results indicate that the consistent, positive effect of vouchers in the current literature is not due to a lower standard among the typical comparison group: public housing. Future studies should focus on conceptualizing and analyzing the protective effect of vouchers beyond comparisons to public housing environments.
\end{abstract}

Keywords: adolescent substance use; adolescent violence; public housing; subsidized housing

This is the author's manuscript of the article published in final edited form as:

Leech, T. G. J. (2012). Subsidized Housing, Public Housing, and Adolescent Violence and Substance Use. Youth \& Society, 44(2), 217-235. http://doi.org/10.1177/0044118X10388821 


\section{Subsidized Housing, Public Housing, and Adolescent Violence and Substance Use}

There is strong evidence that the clustering of poor families in neighborhoods has negative economic and social effects on individuals (Brooks-Gunn, Duncan, \& Aber, 1997; Udayakumar \& Nelson, 1999; Vey, 2007). The spatial concentration of poverty has been associated with problems ranging from limited job access (Gobillon, Selod, \& Zenou, 2007; Wilson, 1978) to school failure (Brooks-Gunn et al., 1997) and poor individual health (Ross \& Mirowsky, 2001). These associations also apply to the issues of teen violence and substance use. Research consistently indicates that neighborhood disadvantage is related to increased adolescent drug abuse, alcohol use, and violent behavior (Elliott et al., 1996; Kubrin \& Weitzer, 2003; MacDonald \& Gover, 2005; Valdez, Kaplan, \& Curtis, 2007).

In turn, this evidence has become the basis for assumptions that substance use and violence among adolescents living in public housing warrants public policy attention (Popkin, Buron, Levy, \& Cunningham, 2000; Schwartz \& Tajbakhsh, 2001). Relying on existing social scientific findings about the effects of concentrated poverty (Massey \& Denton, 1993; R. Sampson \& Lauritsen, 1994; R. J. Sampson, Morenoff, \& Gannon-Rowley, 2002), policy makers have argued that if concentration in impoverished neighborhoods contributes to health risk behaviors, then dispersing public housing residents through residential mobility and mixed-housing should lead to more positive behaviors within the public housing population (Crump, 2003; Khadduri, 2001).

Yet this line of reasoning is susceptible to the ecological fallacy (Good \& Hardin, 2009, p. 170): Information about community-level effects is being used to draw conclusions about individuals' health behaviors. Existing research on adolescent violence and substance use indicates that areas of concentrated disadvantage may be suitable locations for these activities to occur, but the residents of the location may not be the individuals enacting these behaviors (Cohen \& Felson, 1979). In other words, the substantial information about neighborhood disadvantage and negative outcomes does not necessarily indicate a higher rate of problematic behavior among public housing residents.

This misinterpretation of the evidence is important for various reasons. The assumption of higher rates of deviant behavior among public housing residents could result in biased everyday interactions as well as biased academic products. Furthermore, the aforementioned influence on policy has encouraged actions such as razing and renovating buildings (Khadduri, 2001), enforcing restrictive tenancy (U.S. Department of Housing and Urban Development), and increasing access to vouchers (Popkin, Cunningham, \& Burt, 2005) that require a large amount of public spending. Finally, studies of the success of the latter policyhousing vouchers - have been very influential in the urban sociology and housing literature. However, if the assumptions about elevated rates of problem behavior among public housing residents are correct, evaluations of housing vouchers' effects may be biased by low standards within the control group. In other words, it remains unclear whether adolescents living in subsidized housing have higher rates of substance use and violence compared with other, similar teens who do not reside in public housing units.

This article aims to address some of these shortcomings in the existing literature by investigating violence and substance use during late adolescence. This study makes two specific contributions to our understanding of housing and adolescent risk behavior. First, it examines the "exposure effect" of living in public housing in a national sample of adolescents. Second, it explores the effect of living in subsidized housing relative to similar peers who do not reside in public housing.

\section{Housing Voucher's Positive Effects on Problem Behavior}

The increased policy emphasis on "housing choice" and vouchers in the late 1990s was partially based on evidence of widespread social problems among inner-city youth (Duncan \& Ludwig, 2000). At this time, 
increasing numbers of scholars were researching and documenting the association between concentrated poverty and these social problems (for a review, see Small \& Newman, 2001). Policy makers drew on this neighborhood research to advocate plans to deconcentrate poverty, and evaluations of the resulting voucher programs have documented success.

Perhaps the best available evidence of the protective effect of subsidized housing receipt comes from the Moving to Opportunity (MTO) program (Kling, Ludwig, \& Katz, 2005; Ludwig, Duncan, \& Hirschfield, 2001). The MTO provided housing vouchers and support to a subset of families who applied for housing assistance, allowing them to move to low-poverty neighborhoods (Goering \& Feins, 2003). Early results from the program indicate that boys whose families received a housing voucher are significantly less likely to exhibit problem behavior (Duncan \& Ludwig, 2000). Furthermore, those whose families also received assistance/mandates to relocate to low-poverty areas display significantly lower rates of violent crime arrests. More recent findings suggest that the effect on violent crime declines slightly over time but remains significant for the latter group (Kling et al., 2005).

Largely due to its experimental design, the MTO studies have heavily influenced the scholarship on public housing's effects on various social outcomes. However, the experimental design also means that available statistical comparisons are limited to public versus subsidized housing. The MTO provides important information, but it does not answer questions concerning voucher recipients' rates of violence and substance use relative to other families who do not live in public housing units. Failure to investigate this comparison may have contributed to the NIMBY — that is, "not in my backyard"—-phenomenon and general backlash against subsidized housing placement that we have witnessed in certain (largely suburban) areas (Bonastia, 2000; Danielson, 1976; de Souza Briggs, 1998).

\section{Rates of Violence and Substance Use Among Adolescent Public Housing Residents}

It is important to determine if the typical control group—adolescents residing in public housing-has higher rates of problem behavior than other, similar teens, thereby distorting the evidence of positive effect of vouchers. However, available research specific to public housing provides an inconsistent account of the connection between public housing residence and adolescent violence. Where there is evidence of problem behavior, evidence of the connection is nuanced.

Public housing crime rates follow the same trend but tend to be lower than the rates of the cities in which they are located (Davies, 2006). Furthermore, one study finds higher rates of violent crime among public housing teens only among older adolescents living in high-density units (Ireland, Thornberry, \& Loeber, 2003). Younger teens and older teens in less dense housing units show no difference in violence from other populations.

In general, residents living in large (especially high-rise) public housing units report being victimized by violent and drug crime more than other individuals (U.S. Department of Housing \& Urban Development, 1994). Griffiths and Tita (2009) find that the homicides committed in public housing dwellings in one Los Angeles area are more likely to have local victims than the homicides in other similar, low-income neighborhoods, but they are also more likely to be committed by local offenders. Yet, other evidence suggests that a large portion of crimes committed within public housing units are attributable to offenders who are not tenants (Ireland et al., 2003; Pyle, 1976).

The literature on substance use also tends to rely on individual city studies and produce inconsistent findings. There is a paucity of information available, but the limited, nascent literature does not indicate elevated rates of substance use among teens living in public housing. One small-scale survey reports low rates of alcohol and drug use among public housing teens (Rodney \& Mupier, 1997). In addition, a 
comparative analysis of adolescents living in public housing to those in conventional housing finds no distinguishably different problematic alcohol use (Williams, Scheier, Botvin, Baker, \& Miller, 1997).

\section{Individual Behavior Versus Ecological Rates}

So why is the depiction of violent and/or substance abusing public housing tenants so pervasive? It seems to be largely due to a misinterpretation of the social scientific literature. Public housing units are associated with elevated crime rates in the surrounding neighborhood (Holloway \& McNulty, 2003). In addition, public housing projects are more than 5.5 times as likely to be hot spots for crime than other residences (Davies, 2006). However, Fagan and Davies (2004) distinguish between outward and inward contagion in regard to public housing delinquency: outward diffusion would refer to public housing residents leaving the premises to engage in behavior, whereas inward diffusion would refer to nonresidents visiting public housing premises to engage in certain behaviors. They contends that outward diffusion applies primarily to robbery and inward diffusion applies to assault. This consideration paired with past findings about the likely nonresidency of offenders suggests that teen violence and substance use at public housing complexes derives from teens outside the housing unit.

This project is concerned with investigating both the behavior of adolescents living within public housing units and those residing in subsidized housing relative to teens in other housing situations. In general, our understanding about public housing and problematic youth behavior has suffered because individuals have failed to (a) distinguish neighborhood or area crime statistics from the behavior of residents and (b) move beyond subsidized housing versus public housing comparisons. Moreover, the limited scholarship available - especially about substance use-is largely derived from project or city-specific case studies (Griffiths \& Tita, 2009; Holloway \& McNulty, 2003; Ireland et al., 2003; Rodney \& Mupier, 1997; Williams et al., 1997). The current study addresses these shortcomings by using a national sample to investigate rates of violence and substance use among teens residing in public housing and subsidized housing, respectively, and to compare each of these groups to similar teens whose families have not received housing assistance.

\section{Method}

\section{Sample}

The data for this project are based on the children of women who participated in the National Longitudinal Survey of Youth (NLSY). The NLSY is a biannual panel study conducted by the Bureau of Labor Statistics that began in 1979. Originally, the study followed a nationally representative sample of young adults aged 14 to 21 years. Beginning in 1986, data were collected on children ever born to women in the NLSY sample through self-reports and mother interviews. In 1994, the project administered a similar survey specific to children 14 years of age and older-the young adult survey. The analyses in the present study rely on mothers' responses to the NLSY survey and adolescents' responses to the young adult survey. The study cohort consists of 2,530 adolescents aged 14 through 19 who were still residing with their mothers in 2002 or 2004 (these years were pooled to increase the sample size).

\section{Measures}

Control variables. The young adult survey (i.e., the adolescents' reports) sup-plies the data on race, gender, and age. The NLSY survey (i.e., mothers' reports) provides the information on family size, family income, location of residence (both urban/rural and region), and maternal employment, education, and past health risk behavior. Information about mothers' history of health risk behavior includes marijuana use, other drug use, and binge drinking. 
Public/subsidized housing residence. Due to their age and potentially limited knowledge about the specifics of their living situation, data about public housing residence were obtained from the mothers' questionnaire. Mothers were asked if they lived in public housing or received a rent subsidy from the government in the past year. An affirmative answer was followed by a question distinguishing between housing subsidy receipt and residence in public housing projects. These two questions were combined to create three different dummy variables: (a) public or subsidized housing, representing 215 respondents; (b) public housing, representing 125 respondents; and (c) subsidized housing, representing 90 respondents. The second and third variables (public housing and subsidized housing) are mutually exclusive.

Violence and substance use. The variables representing risk behavior come directly from adolescent selfreports. All of the outcome variables are dichotomous and are coded as dummy variables. Violence is recorded as an affirmative response to at least one of the following in the past year: hurt someone badly enough to need a doctor, hit or seriously threatened someone, and or got into a fight at work or school.

The definitions employed for heavy alcohol and heavy marijuana use have been used in several past studies and are also used by the Office of National Drug Control Policy (Muthén \& Muthen, 2000; U.S. Office of National Drug Control Policy, 2004). Heavy alcohol use is defined as drinking more than several times in the past month and having on average more than five drinks at a time. Heavy marijuana use is indicated by use within the past 6 months and at least one of the following: used more than intended, built up a tolerance, tried to "cut down" but failed, caused a health problem (including emotional or psychological), and or limited activities. The two outcomes are combined to represent one variable: "heavy marijuana" or "heavy alcohol use." Any other drug use (huffing, prescription drugs, opiates, cocaine, crack, methamphetamine, heroine) within the past year is indicated by a separate, dummy variable labeled other drugs.

Two percent or less of any variable's observations were missing. Missing data were imputed based on regressions using the mother's risk behavior as well as adolescents' demographic information.

Furthermore, sampling weights were employed in the analyses to account for an oversampling of African Americans and sample attrition. After implementing these weights, the data represent children born to a nationally representative sample of women aged 14 to 21 in 1979.

\section{Statistical Analysis}

Data were analyzed using propensity scores and stratification matching in STATA 9.2. These methods rely on the conceptualization of a "treatment effect." Those cases that receive the treatment (e.g., exposure to public housing) are matched with nontreated control cases (i.e., those in non-assisted housing situations) with a similar likelihood to receive the treatment (Becker \& Ichino, 2002). This methodology improves on regression techniques in two important ways. First, it allows for an emphasis on the analytic conceptualization: it specifically facilitates the comparison of two groups while controlling for important covariants "in the background." Second, propensity score matching allows for the adjustment of a large number of covariates but is not affected by over-parameterization and is less susceptible than regression analysis to collinearity (Rubin, 2006).

Propensity to reside in public housing or subsidized housing was deter-mined based on all of the information reported in Table 1. Notably, this score includes indicators such as the adolescent's race, age, sex, urban residence, geographic region, family income, and the mother's education, employment, age at first birth, and past substance use. Propensity scores were generated individually for (a) public or subsidized housing residence, (b) public housing residence, and (c) subsidized housing residence. 
The goal of the propensity analysis is to "balance" the potentially con-founding variables so that there is no difference in the conditional probability of public housing residence when the sample is stratified into blocks. All of the models were balanced by stratifying the sample into 6 to 7 blocks (at least 5 blocks is customarily accepted as adequate to balance propensity scores, see Cochran, 1968). Each of the propensity scores has a lower threshold around $1 \%$ and upper thresholds ranges from $49 \%$ to $87 \%$, representing the likelihood of living in public or subsidized housing. Furthermore, the propensity adjustment reduces the amount of variance explained by the potentially con-founding variables from around $20 \%$ to $2 \%$ or $3 \%$. As is shown in Table 1 , many predictors are statistically significant in logistic regressions on housing type (subsidized or public housing as one group, subsidized housing only, and public housing only represent three different propensity adjustments), and nearly all of these potential confounders lose significant in the logistic models that adjust for propensity score.

The final analyses use these propensity scores to compute the average treatment effect. Throughout the analyses, standard errors are obtained using 500 bootstrap repetitions based on weights established in the propensity score analysis (Becker \& Ichino, 2002). In addition, all analyses (including descriptive analyses) are limited to the area of common support (Rubin, 2006), so a large number of controls (see Table 1) were excluded from each analysis because their propensity scores greatly differed from any of the public or subsidized housing residents' propensity scores. The result represents the effect of exposure to public or subsidized housing, net of adolescents' conditional likelihood to live in public housing based on important background characteristics.

\section{Results}

\section{Descriptive Results}

Table 2 describes some of the sample's background characteristics. The table reports the weighted means of the cases included within the analysis (i.e., those within the common area of support). Most of the information conforms to expectations based on previous studies. A large majority of the teens live in urban areas, minorities are overrepresented in the subsidized and public housing groups (64\% and 52\%, respectively, versus 21\%), and the average family income of the latter two groups is well below that of the control group. In addition, before controlling for any confounding factors, teens living in subsidized, public, and standard housing have similar rates of problem behavior with one exception. Adolescents residing in subsidized housing have significantly lower rates of heavy marijuana and alcohol use than adolescents residing in public housing.

The mothers' characteristics also differ between the treated and control groups in many expected ways. Interestingly, though, the mothers' characteristics also reveal some differences between the subsidized and public housing groups, providing support for dividing these two samples into separate treatment groups. The public housing and subsidized housing samples both report higher high school dropout rates (19\% and $17 \%$, respectively), unemployment rates (37\% and 50\%, respectively), and single parenting rates (22\% and 26\%, respectively) among mothers than does the control group (high school drop-out, unemployment, and single parenting rates of $7 \%, 19 \%$, and 5\%, respectively). However, the subsidized housing mothers' alcohol and drug use is closer to that of the control group than the behavior of mothers living in public housing. The mothers of teens living in subsidized housing also have significantly lower rates of lifetime drug use (39\% vs. $57 \%$, respectively) and binge drinking in the past year (2\% vs. $15 \%$, respectively) than the rates among mothers of teens living in public housing. On average, these mothers have significantly lower family incomes, perhaps due to the QHWRA requirement that $75 \%$ of vouchers go to families with incomes less than $30 \%$ of the median income rate.

Analytic Results 
When public housing and subsidized housing residents are examined as one, combined group (see Panel A), only one significant result emerges. The combined group has lower levels of violence compared to the control group (i.e., a 5\% lower prevalence). In contrast, these results suggest that there is no significant effect of living in public/subsidized housing either on marijuana and alcohol use (showing a $0.6 \%$ average treatment effect) or on hard drug use (-2.5\% ATT).

The results provide more consistent information when separated into subsidized housing and public housing residence. When examined as two distinct groups (Panels B and C separate the groups into public housing residents and subsidized housing residents, respectively), the results show more distinct and patterns. As is evident in Panel B, the behavior of teens residing in public housing does not significantly differ from the behavior of comparable teens in other, nonsubsidized housing situations. The only result that is even marginally significant is an elevated rate of heavy marijuana and alcohol use $(p=.068)$.

The results of the analysis specific to subsidized housing (see Panel C) differ greatly from those on the public housing sample. When compared with other teens with similar propensity scores, teens residing in subsidized housing report lower levels of each risk behavior (although the effect on heavy marijuana or alcohol use is only marginally significant, $\mathrm{p}=.071$ ). The analyses translate into a $9 \%$ lower rate of violence, $8 \%$ lower prevalence of heavy marijuana or alcohol use, and a $5 \%$ decrease in other drug use.

It is important to recognize that the treatment effects that have been reported thus far represent absolute values. For example, Table 3 reports a 5\% decrease in other drug use, because the prevalence among subsidized housing residents is $11 \%$ compared to a $16 \%$ adjusted prevalence within the control group. Hence, the 5\% average treatment effect is actually a 31\% decrease in the rate of drug use (i.e., .05/.16). Figure 1 illustrates this type of relative difference in risk behavior rates for each of the subgroups. The graphic representation more plainly displays that the largest effects are evident within the subsidized housing group, and each of these effects represents a reduction in health risk behavior. The last cluster in the figure also shows that housing assistance in general - whether it is receiving public housing or subsidized housing assistance-is associated with lower rates of violence and hard drug use among teens.

\section{Discussion and Conclusions}

Due to the extraordinary amount of evidence documenting a relationship between concentrated disadvantage and social problems (Small \& Newman, 2001), residents of public housing units are often labeled as problematic youth (Palmer, Ziersch, Arthurson, \& Baum, 2004). Contrary to these common conceptions, the adolescents receiving housing assistance in this study exhibited rates of marijuana, alcohol, and other drug use that are indistinguishable from similar peers, and they have significantly lower rates of violence than their matched comparisons. On disaggregation of public housing and subsidized housing residence, the stigma of public housing is further challenged. There are no significant differences between the behavior of adolescents residing in public housing and that of similar peers receiving no housing assistance.

Previous studies report elevated rates of violence victimization among public housing residents, and adolescents in particular (Durant, 2000). The present study's results do not contradict these and other similar findings; rather past results may help with the interpretation of the present findings. When placed within the context of the existing literature, the results suggest that teen public housing residents may be better characterized as a population at risk for victimization rather than one at specific risk of engaging in problem behaviors. That is, above and beyond the issues faced by teens in other, similarly disadvantaged situations, this study finds that residing in public housing does not expose teens to a greater risk of committing violence or using hard drugs. 
Furthermore, in line with existing findings (Kling et al., 2005), the teens in this study who reside in subsidized housing have significantly lower rates of hard drug use and violence than comparable peers and marginally significant $(\mathrm{p}=.071)$ lower rates of heavy alcohol or marijuana use. Thus, the present findings strengthen the information provided by the influential MTO studies, revealing a positive effect of voucher receipt even when the comparison group represents teens outside public housing units. The present study helps to alleviate concerns that the documented success of vouchers is due to the high rates of problem behavior among the comparison (public housing) group.

These disaggregated results compared with the results on the combined group should induce caution among researchers and policy makers concerned about youth outcomes. The results on the combined group - that is, teens living in subsidized or public housing —indicate that receiving any housing assistance is associated with significantly lower rates of violence and marginally significant lower rates of hard drug use. Yet it should be acknowledged that the very large treatment effect associated with subsidized housing recipients drives this association. This recognition does not dismiss the potentially protective effect of receiving housing assistance versus living in other housing situations that may be less stable and consistent, but it does indicate that housing assistance recipients should not be thought of or referred to as one, homogeneous population.

Our results show that, even after the reforms of 1998 that intended to improve the environment of public housing residents by razing and/or refurbishing large-scale, densely populated housing projects and enforcing restrictive tenancy (Popkin et al., 2000; Popkin et al., 2005; Schwartz \& Tajbakhsh, 2001), the reality of teens living in public housing units differs from that of teens receiving housing vouchers. In fact, supplemental analyses indicate that the situation of 2004 residents of public housing is more similar to 1996 residents of public housing (prior to the reforms) than to 2004 residents of subsidized housing (see Figure 1). Thus, in the future these groups should be disaggregated in scholars' analytic frames.

These groups' differential situations also give cause for policy makers to rethink the massive razing and dislocation (as opposed to relocation) policies associated with public housing units. My results strengthen the argument to continue or expand subsidized housing programs. However, the results also suggest that razing policies driven by the intent to improve youth behavioral outcomes may not be warranted because there are no baseline higher rates of problem behavior among these youth. Evidence on these policies in Chicago indicates that the social situations and weakened ties associated with relocation of large public housing populations may lead to higher rates of violent behavior when these residents arrive in their new neighborhoods (Hagedorn \& Rauch, 2004). Furthermore, existing research indicates that public housing environments may lead to inward diffusion of problem behavior (Fagan \& Davies, 2004). If this is the case, the present analyses indicate that policy makers and practitioners may want to consider modifying existing public housing environments, not mass relocation of the residents.

\section{Limitations and Future Directions}

Together these analyses help to address the paucity of information specific to teens living in public housing units and further clarify the positive effect of subsidized housing, but they have their limits. The primary limitation is associated with the nature of the data set. Due to the format of the NLSY, many of these children were born to young mothers. Hence, the population examined in the study might be considered a high-risk group. The research question and design of the analysis - that is, comparing public and subsidized housing residents to other teens with similar individual and family characteristics within a common area of support—partially account for this limitation, but the results should be considered with some caution. 
The methodology may also introduce concern about limiting the analysis to the area of common support (and thereby excluding a substantial number of respondents). However, none of the "treated" cases (i.e., the residents of subsidized or public housing) were dropped due to this consideration-all of them could be paired with a control case. In other words, the overlap in the distribution of the conditional probability of receiving housing assistance included the entire range for the public housing and subsidized housing groups (Titus, 2007).

Finally, the study is further limited due to the lack of information on the type of public housing in which respondents reside. Previous research has established a differential relationship between public housing and problem behaviors based on the size and density of the unit (Ireland et al., 2003), but this information was not available in the data set.

Despite the limits of this study, the results provide interesting and important suggestions for future scholars and practitioners. First, they suggest that the depiction of risk behavior among teens in public housing needs to be clarified. Labeling or stereotyping teens living in public housing as violent and/or drug users is misleading. Second, the results illustrate the value of distinguishing between public housing and subsidized housing populations in academic studies, government policies, and common discussions of adolescent health risk behaviors. Third, the present results indicate that the consistent, positive effect of vouchers is not due to a lower standard among the typical comparison group: public housing.

Thus, more research needs to be done to clarify the causal mechanisms that explain the protective effect of housing vouchers. In these future analyses, the conceptual and analytic frames must move beyond a focus on the environment of public housing residents and instead place subsidized housing in the referent category. Future research is critical to our understanding of the ways housing vouchers protect against problem behavior when compared to other, nonassisted housing environments.

\section{Acknowledgments}

The author would like to thank Dr. Claire Gibbons, Dr. Bernice Pescosolido, and Dr. Carrie Foote for very helpful comments on earlier drafts. I also greatly appreciate the support provided by the New Connections Program at the Robert Wood Johnson Foundation.

\section{Declaration of Conflicting Interests}

The author(s) declared that they had no conflicts of interest with respect to their authorship or the publication of this article.

\section{Funding}

The author(s) disclosed that they received the following support for their research and/or authorship of this article: This project and article was supported by a Robert Wood Johnson Foundation New Connections Grant. 


\section{References}

Becker, S., \& Ichino, A. (2002). Estimation of average treatment effects based on propensity scores. Stata Journal, 2, 358-377.

Bonastia, C. (2000). Why did affirmative action in housing fail during the Nixon era? Exploring the "institutional homes" of social policies. Social Problems, 47, 523-542.

Brooks-Gunn, J., Duncan, G., \& Aber, J. (1997). Neighborhood poverty: Context and consequences for children. New York: Russell Sage Foundation.

Cochran, W. (1968). The effectiveness of adjustment by subclassification in removing bias in observational studies. Biometrics, 24, 295-313.

Cohen, L., \& Felson, M. (1979). Social change and crime rate trends: A routine activity approach. American Sociological Review, 44, 588-608.

Crump, J. R. (2003). The end of public housing as we know it: Public housing policy, labor regulation and the U.S. city. International Journal of Urban and Regional Research, 27, 179-187.

Danielson, M. (1976). The politics of exclusionary zoning in suburbia. Political Science Quarterly, 91(1), 1-18.

Davies, G. (2006). Crime, neighborhood, and public housing. New York, NY: LFB Scholarly.

de Souza Briggs, X. (1998). Brown kids in white suburbs: Housing mobility and the many faces of social capital. Housing Policy Debate, 9, 177-221.

Duncan, G., \& Ludwig, J. (2000). Can housing vouchers help poor children? Washington, DC: Brookings Institution.

DuRant, R., Altman, D., Wolfson, M., Barkin, S., Kreiter, S., \& Krowchuk, D. (2000). Exposure to violence and victimization, depression, substance use, and the use of violence by young adolescents. The Journal of Pediatrics, 137(5), 707-713.

Elliott, D., Wilson, W., Huizinga, D., Sampson, R., Elliott, A., \& Rankin, B. (1996). The effects of neighborhood disadvantage on adolescent development. Journal of Research in Crime and Delinquency, 33, 389.

Fagan, J., \& Davies, G. (2004). The natural history of neighborhood violence. Journal of Contemporary Criminal Justice, 20(2), 127.

Gobillon, L., Selod, H., \& Zenou, Y. (2007). The mechanisms of spatial mismatch. Urban Studies, 44, 2401-2428.

Goering, J., \& Feins, J. (2003). Choosing a better life: Evaluating the moving to opportunity social experiment. Washington, DC: Urban Institute Press.

Good, P., \& Hardin, J. (2009). Common errors in statistics (and how to avoid them). Hoboken, NJ: Wiley.

Griffiths, E., \& Tita, G. (2009). Homicide in and around public housing: Is public housing a hotbed, a magnet, or a generator of violence for the surrounding community? Social Problems, 56, 474-493.

Hagedorn, J., \& Rauch, B. (2004, July). Variations in urban homicide: Chicago, New York City and global urban policy. Paper presented at “City Futures: An International Conference on Globalism and Urban Change,” University of Illinois at Chicago. Retrieved from http://www.uic.edu/cuppa/cityfutures/papers/webpapers/cityfuturespapers/session3_2/3_2variations.pdf

Holloway, S., \& McNulty, T. (2003). Contingent urban geographies of violent crime: Racial segregation and the impact of public housing in Atlanta. Urban Geography,24, 187-211.

Ireland, T., Thornberry, T., \& Loeber, R. (2003). Violence among adolescents living in public housing: A two-site analysis. Criminology \& Public Policy,3(1), 36.

Khadduri, J. (2001). Deconcentration: What do we mean? What do we want? Cityscape, 5(2), 69-84.

Kling, J., Ludwig, J., \& Katz, L. (2005). Neighborhood effects on crime for female and male youth: Evidence from a randomized housing voucher experiment. Quarterly Journal of Economics, 120(1), 87-130.

Kubrin, C., \& Weitzer, R. (2003). Retaliatory homicide: Concentrated disadvantage and neighborhood culture. Social Problems, 50, 157-180.

Ludwig, J., Duncan, G., \& Hirschfield, P. (2001). Urban poverty and juvenile crime: Evidence from a randomized housingmobility experiment. Quarterly Journal of Economics, 116, 655-679.

MacDonald, J., \& Gover, A. (2005). Concentrated disadvantage and youth-on-youth homicide: Assessing the structural covariates over time. Homicide Studies, 9(1), 30.

Massey, D., \& Denton, N. (1993). American apartheid: Segregation and the making of the underclass. Cambridge, MA: Harvard University Press.

Muthén, B., \& Muthen, L. (2000). The development of heavy drinking and alcohol related problems from ages 18 to 37 in a U.S. national sample. Journal of Studies on Alcohol, 61, 290-300.

Palmer, C., Ziersch, A., Arthurson, K., \& Baum, F. (2004). Challenging the stigma of public housing: Preliminary findings from a qualitative study in South Australia. Urban Policy and Research, 22, 411-426.

Popkin, S., Buron, L., Levy, D., \& Cunningham, M. (2000). The Gautreaux legacy: What might mixed-income and dispersal strategies mean for the poorest public housing tenants? Housing Policy Debate, 11, 911-942.

Popkin, S., Cunningham, M., \& Burt, M. (2005). Public housing transformation and the hard to house. Housing Policy Debate, 16(1), 1-24

Pyle, G. (1976). Spatial and temporal aspects of crime in Cleveland, Ohio. American Behavioral Scientist, 20, 175-196.

Rodney, H., \& Mupier, R. (1997). African-American youth in public housing showing low alcohol and drug use. Journal of Child and Adolescent Substance Abuse, 6(4), 55-73.

Ross, C., \& Mirowsky, J. (2001). Neighborhood disadvantage, disorder, and health. Journal of Health and Social Behavior, 42, 258-276.

Rubin, D. (2006). Matched sampling for causal effects. Cambridge, UK: Cambridge University Press. 
Sampson, R., \& Lauritsen, J. (1994). Violent victimization and offending: Individual-, situational-, and community-level risk factors. In A. Reiss \& J. Roth (Eds.), Understanding and preventing violence: Consequences and control, 1-115.

Sampson, R. J., Morenoff, J. D., \& Gannon-Rowley, T. (2002). Assessing “neighborhood effects”: Social processes and new directions in research. Annual Review of Sociology, 28, 443-478.

Schwartz, A., \& Tajbakhsh, K. (2001). Mixed-income housing as social policy: The case for diminished expectations. Paper presented at the annual meeting of the Urban Affairs Association, Los Angeles, CA.

Small, M., \& Newman, K. (2001). Urban poverty after the truly disadvantaged: The rediscovery of the family, the neighborhood, and culture. Annual Review of Sociology, 27(1), 23-45.

Titus, M. (2007). Detecting selection bias, using propensity score matching, and estimating treatment effects: An application to the private returns to a master's degree. Research in Higher Education, 48, 487-521.

Udayakumar, S. P., \& Nelson, L. (1999). Concentrated poverty: Causes, effects, and solutions. Minneapolis: Institute on Race \& Poverty, University of Minnesota School of Law.

U.S. Department of Housing \& Urban Development. (1994). Survey of public housing and residents: Crime and crime prevention in public housing. Research Triangle Park, NC: Author.

U.S. Office of National Drug Control Policy. (2004). Predicting heavy drug use: Results of a longitudinal study, youth characteristics describing and predicting heavy drug use by adults. Retrieved from http://purl.access.gpo.gov/GPO/LPS79884

Valdez, A., Kaplan, C. D., \& Curtis, R. L., Jr. (2007). Aggressive crime, alcohol and drug use, and concentrated poverty in 24 U.S. urban areas. American Journal of Drug and Alcohol Abuse, 33, 595-603.

Vey, J. S. (2007). Restoring prosperity: The state role in revitalizing America's older industrial cities. Washington, DC: Brookings Institution Metropolitan Policy Program.

Williams, C., Scheier, L. M., Botvin, G. J., Baker, E., \& Miller, N. (1997). Risk factors for alcohol use among inner-city minority youth: A comparative analysis of youth living in public and conventional housing. Journal of Child and Adolescent Substance Abuse, 6(1), 69-89.

Wilson, W. J. (1978). The declining significance of race: Blacks and changing American institutions. Chicago, IL: University of Chicago Press. 


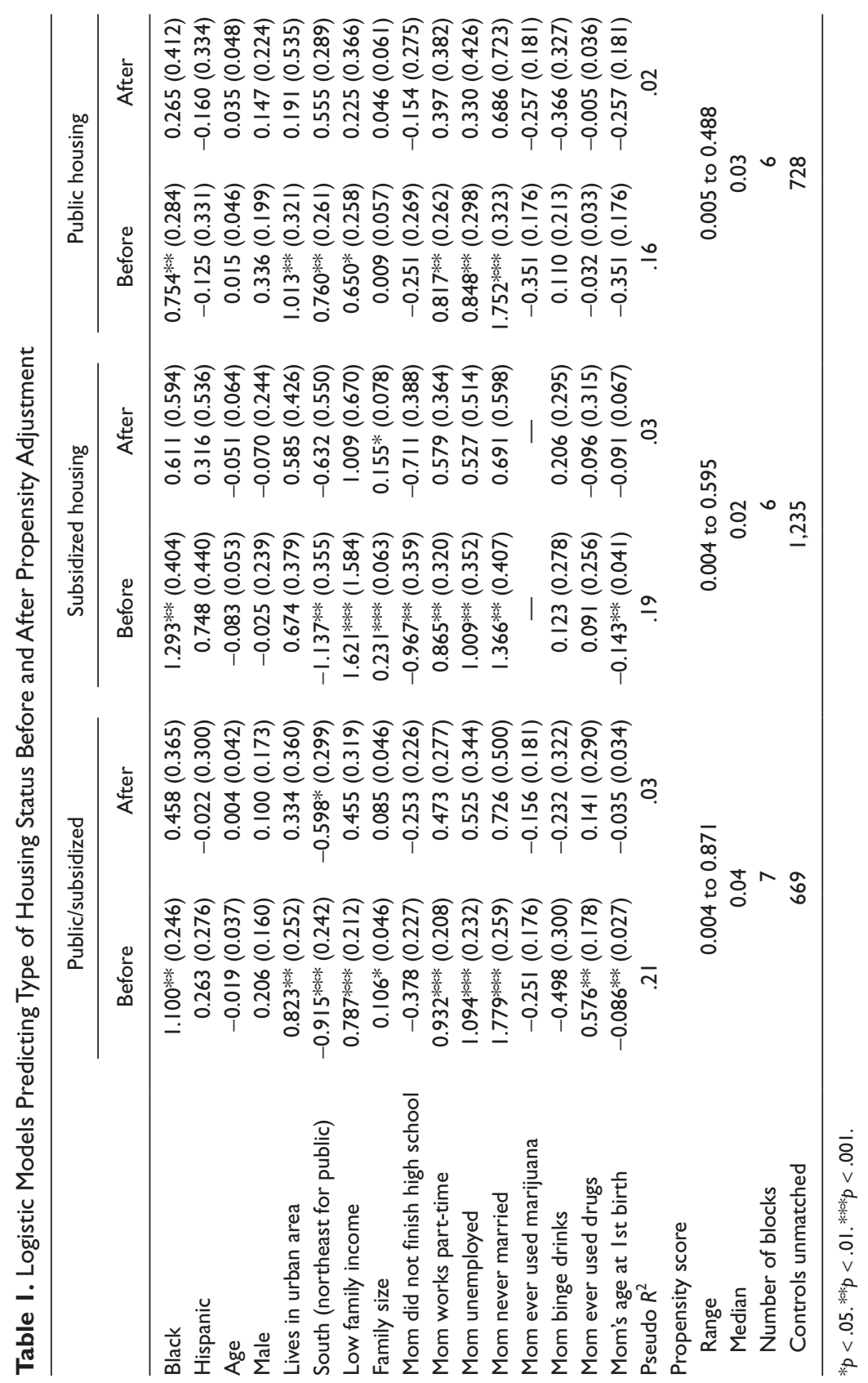


Table 2. Sample Characteristics (Weighted Means)

\begin{tabular}{lccc}
\hline & $\begin{array}{c}\text { Control group } \\
(n=2,315)\end{array}$ & $\begin{array}{c}\text { Subsidized } \\
\text { housing }(n=90)\end{array}$ & $\begin{array}{c}\text { Public housing } \\
(n=125)\end{array}$ \\
\hline Youth characteristics & $14 \%$ & $50 \%$ & \\
Black & $7 \%$ & $14 \%$ & $43 \%$ \\
Hispanic & $79 \%$ & $36 \%$ & $9 \%$ \\
Other race & 17 & 18 & $48 \%$ \\
Age (years) & $51 \%$ & $49 \%$ & 17 \\
Male & $62 \%$ & $82 \%$ & $59 \%$ \\
Lives in an urban area & 3.8 people & 3.6 people & 3.4 people \\
Family size & 39,750 & $18,521 * *$ & 22,628 \\
Family income (US\$) & & & \\
Mother characteristics & $7 \%$ & $17 \%$ & $19 \%$ \\
Did not finish high school & $19 \%$ & $50 \%$ & $37 \%$ \\
Unemployed & $44 \%$ & $18 \%$ & $24 \%$ \\
Works full-time & $5 \%$ & $22 \%$ & $26 \%$ \\
Never married & $58 \%$ & $61 \%$ & $70 \%$ \\
Ever used marijuana & $32 \%$ & $39 \% *$ & $57 \%$ \\
Ever used drugs & $8 \%$ & $2 \% * *$ & $15 \%$ \\
Binge drinker & 22 & 19 & 20 \\
Age at Ist birth (years) & & & \\
Health risk behaviors & $13 \%$ & $12 \%$ & $18 \%$ \\
Violence & $31 \%$ & $29 \% *$ & $51 \%$ \\
Heavy marijuana or alcohol & $11 \%$ & $11 \%$ & $15 \%$ \\
Other drugs & & & \\
\hline
\end{tabular}

Statistically significant differences between the subsidized and public housing samples are represented by $* p<.05$. ${ }^{*} p<.01$. 
Table 3. Stratified Matching Estimates of Public and Subsidized Housing Effect, 2004

\begin{tabular}{|c|c|c|c|c|c|c|}
\hline & \multicolumn{2}{|c|}{ Panel A } & \multicolumn{2}{|c|}{ Panel B } & \multicolumn{2}{|c|}{ Panel C } \\
\hline & $\begin{array}{c}\text { ATT } \\
\text { Public/ } \\
\text { subsidized } \\
\text { housing }\end{array}$ & $\begin{array}{l}\text { Standard } \\
\text { error }\end{array}$ & $\begin{array}{c}\text { ATT } \\
\text { Public } \\
\text { housing }\end{array}$ & $\begin{array}{l}\text { Standard } \\
\text { error }\end{array}$ & $\begin{array}{c}\text { ATT } \\
\text { Subsidized } \\
\text { housing }\end{array}$ & $\begin{array}{l}\text { Standard } \\
\text { error }\end{array}$ \\
\hline Violence & $-0.052^{*}$ & 0.025 & -0.028 & 0.021 & $-0.090 *$ & 0.041 \\
\hline $\begin{array}{l}\text { Marijuana } \\
\text { or drinking }\end{array}$ & 0.006 & 0.027 & 0.083 & 0.043 & -0.082 & 0.048 \\
\hline Other drugs & -0.025 & 0.018 & -0.002 & 0.029 & $-0.050 *$ & 0.024 \\
\hline
\end{tabular}

Note: ATT refers to the average treatment effect on treated, and can be understood as the overall difference in prevalence. Estimates adjust for race, age, gender, urban residence, geographic region, family income, family size, and mother's education, employment, marital status, marijuana use, alcohol consumption, drug use, and age at first birth. Standard errors are bias-corrected and were obtained with 500 bootstrap repetitions.

$*_{p}<.05$. 


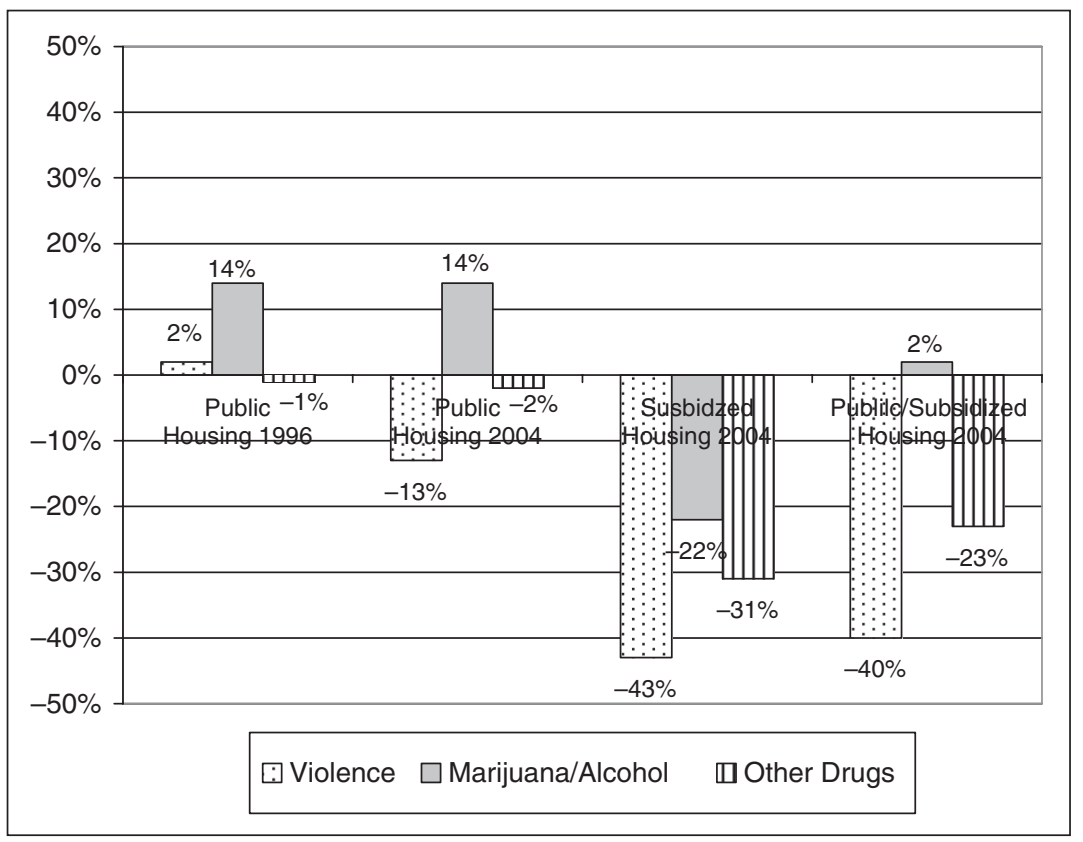

Figure I. Relative differences in problem behavior based on comparisons to nonassisted families (ATT as a percentage of the prevalence of the behavior) 